Journal of Animal and Veterinary Advances 11 (3): 400-403, 2012

ISSN: $1680-5593$

(C) Medwell Journals, 2012

\title{
The New Pest Cydalima perspectalis (Walker, 1859) (Lepidoptera: Crambidae) in Turkey
}

\author{
Erdem Hizal, Muhsin Kose, Canan Yesil and Done Kaynar \\ Department of Forest Entomology and Protection, Faculty of Forestry, \\ Istanbul University, 34473 Bahcekoy, Sariyer, Istanbul, Turkey
}

\begin{abstract}
Cydalima perspectalis (Walker, 1859) is an invasive alien species of East Asia origin. In Europe, it was reported for the first time in 2007 in Germany. Following years, the Cydalima perspectalis (Walker, 1859) continued to spread in Germany and nearby countries. The species has now also reached the European side of Istanbul in Turkey. In this research, C. perspectalis distribution and host plants were investigated in Istanbul.
\end{abstract}

Key words: Cydalima perspectalis, crambidae, alien species, Buxus sempervirens, Turkey, Istanbul

\section{INTRODUCTION}

Cydalima perspectalis (Walker, 1859) is an invasive alien species of East Asia origin. The natural range of the C. perspectalis is the humid subtropical regions of East Asia, India, China, Japan, Korea and Russian Far East (Mally and Nuss, 2010). It has been identified as the most important pest of Buxus. Cydalima perspectalis (Walker, 1859) is also known by the synonym Diaphania perspectalis, Glyphodes perspectalis. In Europe, it was reported for the first time in 2007 in Germany (May, 2007 in the city of Weil am Rhein and its surroundings).

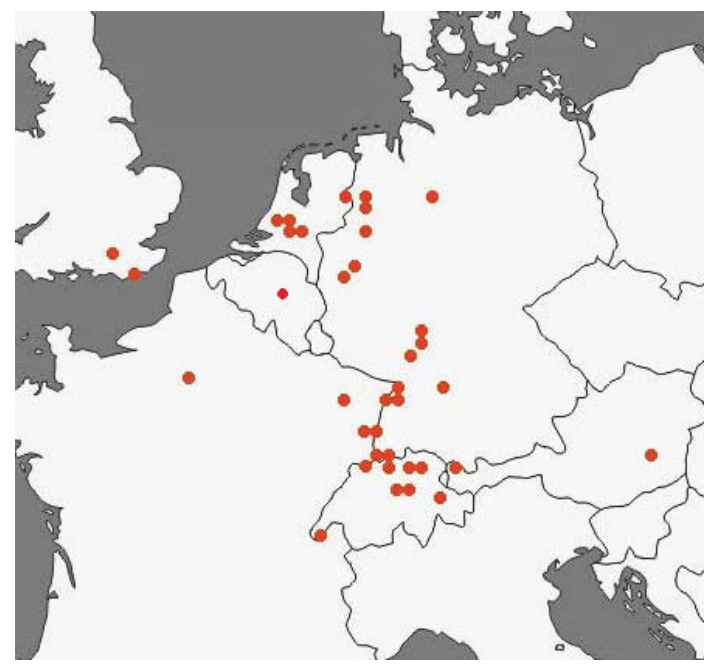

Fig. 1: Distribution of Cydalima perspectalis in Europe (Van der Straten and Muus, 2010)
Following years, the Cydalima perspectalis (Walker, 1859) continued to spread in Germany and nearby countries like Switzerland in 2007, United Kingdom in 2008, Netherlands in 2008, France in 2008, Austria in 2009 and Belgium in 2010 (Fig. 1) (Van der Straten and Muus, 2010). Cydalima perspectalis larvae feed on leaves and shoots while severe infestations can lead to almost complete defoliation of the Buxus. The species has now also reached the European side of Istanbul in Turkey.

\section{MATERIALS AND METHODS}

The adult $C$. perspectalis were identified in the campus of Istanbul University, Faculty of Forestry for the first time on 15th June, 2011. From that date, Buxus sp. were observed in the campus. Larvae and pupae were seen on Buxus sempervirens and B.s. cv. aureavariegata on July 25 th and they were brought to the laboratory for examinations. The adult $C$. perspectalis began to be seen both in the campus and laboratory on July 30th. The presence of these pests and the damaged host plant were investigated between June 20th and July 30th in parks and gardens in Istanbul.

\section{RESULTS AND DISCUSSION}

The eggs are translucent and are laid in a flat sheet, overlapping each other in clusters of about 8-18 eggs on the underside of the box leaves. The average egg size is $1 \mathrm{~mm}$ (Fig. 2a). Mature larvae retain the green ground colour to their bodies and develop a striking of thick black and thin white stripes along the lenght of the body with

Corresponding Author: Erdem Hizal, Department of Forest Entomology and Protection, Faculty of Forestry, Istanbul University, 34473 Bahcekoy, Sariyer, Istanbul, Turkey 

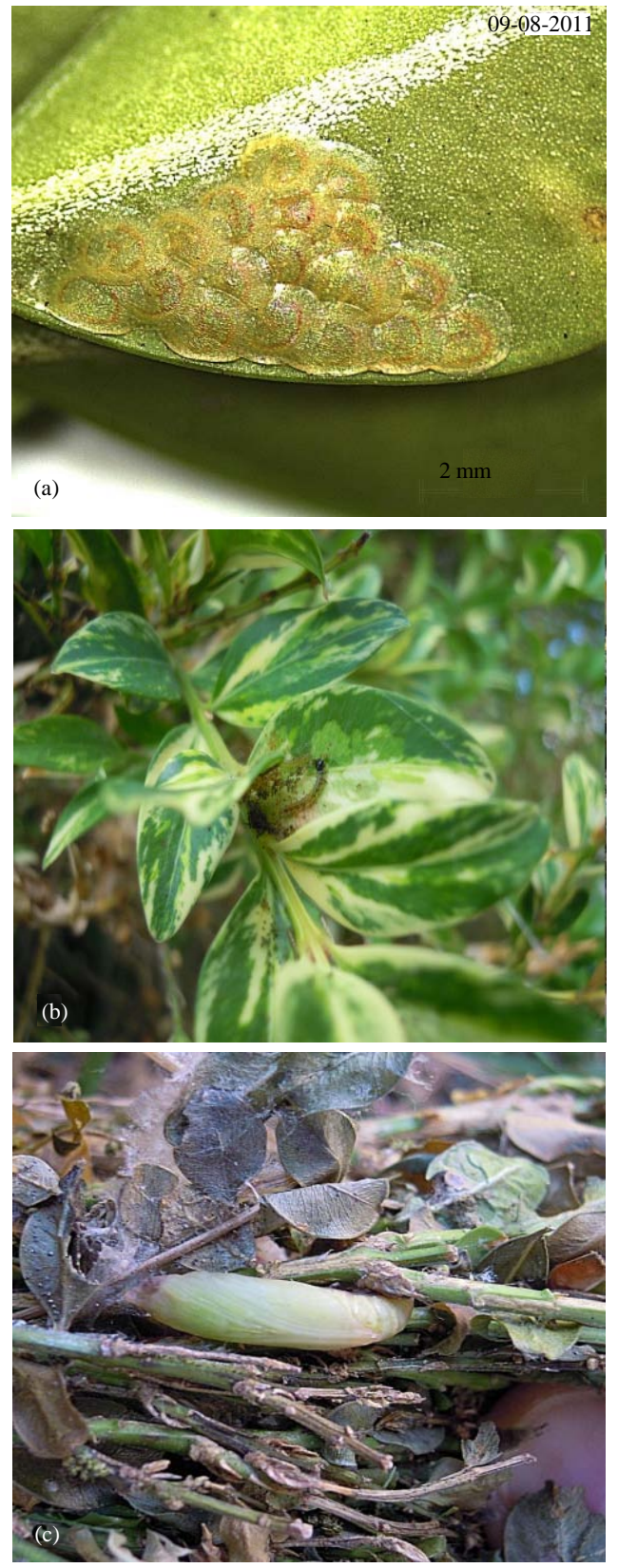

Fig. 2: a) C. perspactalis eggs; b) larvae and c) pupae

large black dots outlined in white on the dorsal side (Fig. 2b). The average length of mature larvae was measured $3.8 \mathrm{~cm}$ (number of sample, $\mathrm{n}=30$ ). Pupae is initially green with dark stripes on the dorsal surface while older pupae turn brown. It is concealed in a cocoon of white webbing spun among the leaves and twings (Fig. 2c). The average length of pupae was measured $1.9 \mathrm{~cm}(\mathrm{n}=30)$. The adults have a thick dark brown border of uneven width around the edges of the white colured wings.
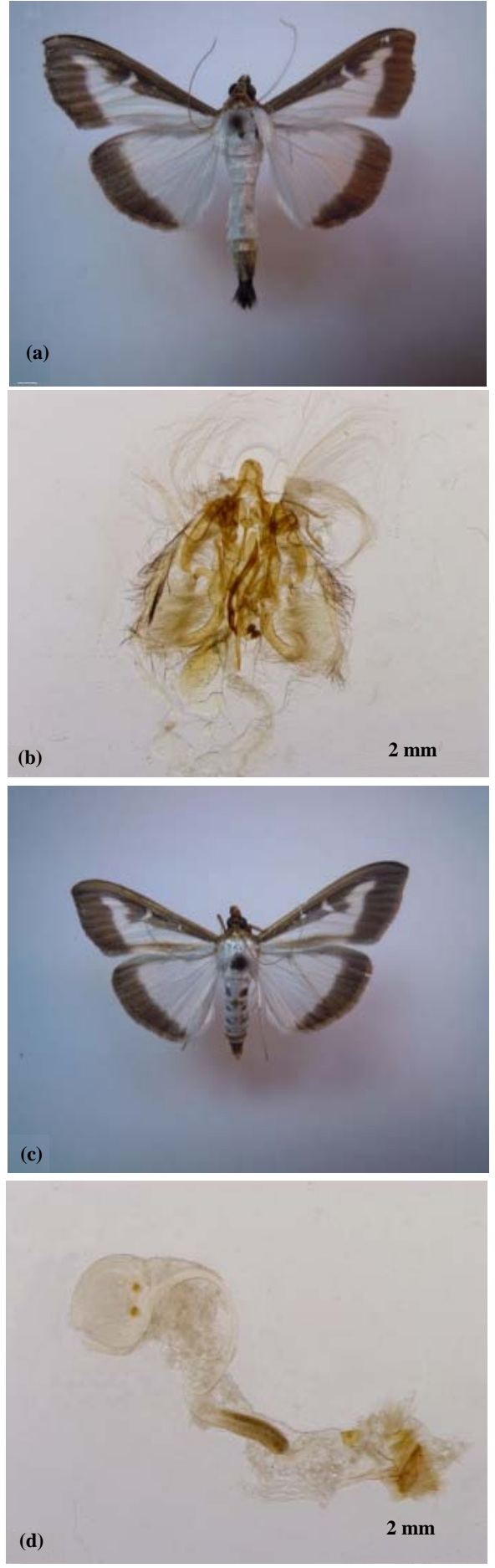

Fig. 3: Cydalima perspectalis adults; a) male; b) male genitalia; c) female and d) female genitalia

The forewings have white extension to the central white portion of the wing which extends into the brown border towards the front of the wing (Fig. 3). The average 
adult wingspan was measured $3.8 \mathrm{~cm}(\mathrm{n}=30)$. No significant difference was found between female and male wingspan. C. perspectalis was identified in Sariyer district (Bahcekoy, Emirgan, Haciosman, Yenikoy, Zekeriyakoy) by the survey that took place on June 20th and July 30th in the parks and gardens in Istanbul. It was determined that damage was strong on Buxus sp., in Sariyer district (Fig. 4 and 5).

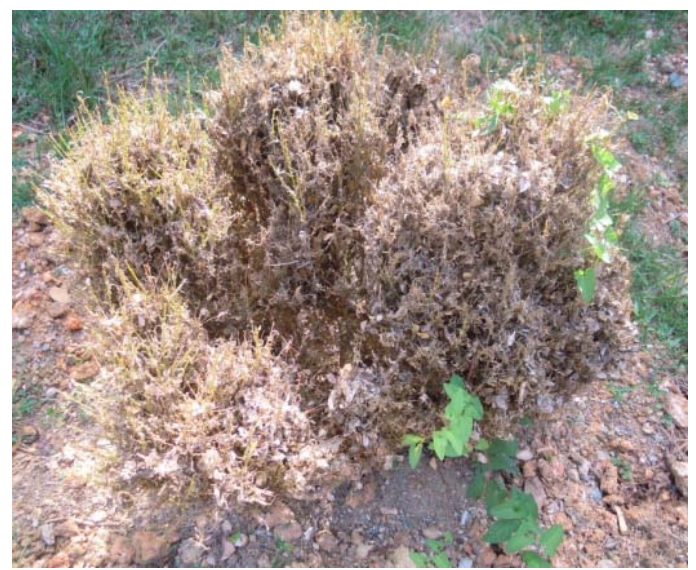

Fig. 4:B. sempervirens affected by $C$. perspectalis (Sariyer district)
During the investigation, C. perspectalis host plants were examined and it was observed that only B. sempervirens and B.s. cv. aureavariegata were damaged.

Cydalima perspectalis has been reported for the first time in the European side of Istanbul in Turkey while the pest has been effective particularly at Istanbul's European side in Sariyer district.

Cydalima perspectalis was not detected in the Anatolian side of Istanbul. However, it is possible that the adult Cydalima perspectalis can fly and pass to Anatolian side and cause damage in Buxus sp., in a short while Cydalima perspectalis caused severe damage on Buxus sp., in parks and gardens in Sariyer district as a result of extensive use of this plant in these areas. Cydalima perspectalis cause serious damage on Buxus sp.

The plant loses all the leaves in a short period. There are two natural Buxus species (Buxus balearica, B. sempervirens) in Turkey (Yaltirik and Efe, 2000). Cydalima perspectalis is a new harmful species that pose a great threat to both natural Buxus sp. and also the ones used in the parks and gardens.

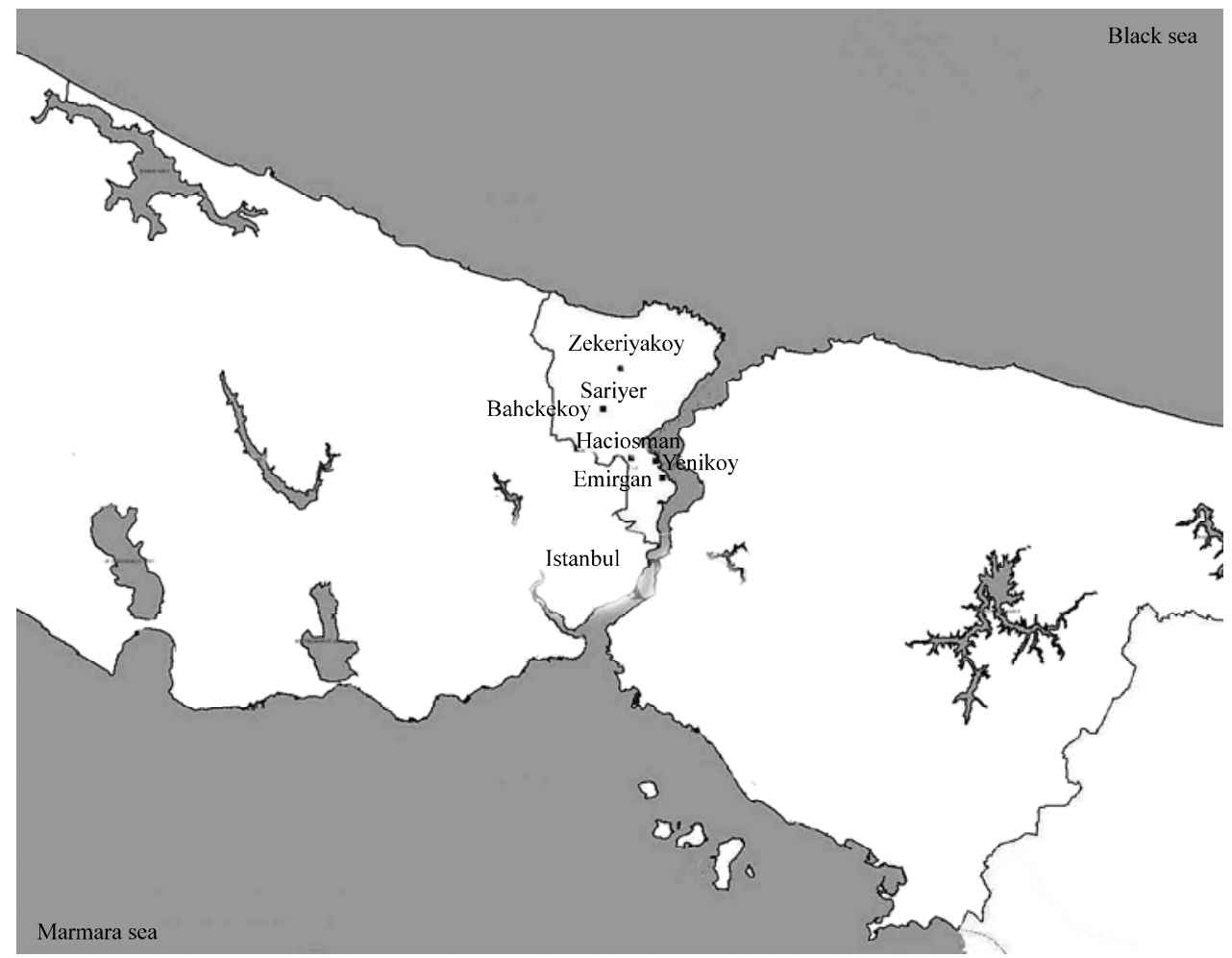

Fig. 5: Distribution of Cydalima perspectalis in Istanbul 


\section{CONCLUSION}

It was reported that Cydalima perspectalis cause damage on Buxus microphylla, B. sempervirens, B. sinica, Euonymus japonicus, E. Alata, Ilex purpurea (Van der Straten and Muus, 2010; Kawazu et al., 2007, 2010; Maruyama, 1993; Korycinska and Eyre, 2009). According to this study investigation, $C$. perpectalis damaged only $B$. sempervirens and B.s. $c v$. aureavariegata at Istanbul's European side. It is possible that Cydalima perspectalis has entered Turkey from China and Europe on imported plants.

There is not enough information about the biology of Cydalima perspectalis. It is reported to be 2 or 3 generations per year in Germany (Korycinska and Eyre, 2009). Detailed studies are required about the biology, distribution, chemical and biological control methods of Cydalima perspectalis in Turkey.

\section{REFERENCES}

Kawazu, K., H. Honda, S. Nakamura and T. Adati, 2007. Identification of sex pheromone components of the box tree pyralid, Glyphodes perspectalis. J. Chem. Ecol., 33: 1978-1985.
Kawazu, K., S. Nakamura and T. Adati, 2010. Rearing of the box tree pyralid, Glypodes perspectalis, larvae using an artificial diet. Applied Entomol. Zool., 45: 163-168.

Korycinska, A. and D. Eyre, 2009. Box tree caterpillar Diaphania perspectalis. Fera Plant Pest and Disease Factsheets, The Food and Environement Research Agency, UK.

Mally, R. and M. Nuss, 2010. Phylogeny and nomenclature of the box tree moth, Cydalima perspectalis (Walker, 1859) comb. n., which was recently introduced into Europe Lepidoptera: Pyraloidea: Crambidae: Spilomelinae. Eur. J. Entomol., 107: 393-400.

Maruyama, T., 1993. Life cycle of the box-tree pyralid, Glyphodes perspectalis (Walker) (Lepidoptera: Pyralidae). IV. Effect of various host plants on larval growth and food utilization. Jpn. J. Applied Entomol. Zool., 7: 117-122.

Van der Straten, M.J. and T.S.T. Muus, 2010. The box tree pyralid, Glyphodes perspectalis (Lepidoptera: Crambidae), an invasive alien moth ruining box trees. Proc. Neth. Entomol. Soc., 21: 107-111.

Yaltirik, F. and A. Efe, 2000. Dendrology Handbook, Gymnospermae-Angiospermea. Faculty of Forestry Publication, Istanbul Universitesi, Turkey. 